\title{
Level of awareness, knowledge and perception on COVID-19among pregnant women attending antenatal clinics in Central Hospital Benin City, Edo state
}

\author{
Sunday Eghosasere Omozuwa, ${ }^{1}$ Noel Ebehiremen Uwaibi ${ }^{2}$ \\ ${ }^{1}$ Department of Obstetrics and Gynaecology; ${ }^{2}$ Department of Community Health, Edo State University \\ Uzairue, Edo State, Nigeria
}

\begin{abstract}
Coronavirus disease (COVID-19) is an infectious viral disease caused by severe acute respiratory syndrome coronavirus-2, which affects mainly the respiratory system and was first discovered during an outbreak in Wuhan community in China December 2019. The outbreak was declared a pandemic by World Health Organization (WHO) March, $11^{\text {th }} 2020$ and a worldwide public health response has been engaged to address the impact. A descriptive cross sectional survey was utilized. A self- administered questionnaire on awareness, knowledge and perception of COVID-19 infection was administered to a total 420 pregnant women attending antenatal clinic in central Hospital Benin City for Data collection. Four hundred and fourteen $(98.6 \%)$ of the respondents were aware of COVID-19 and 274 (66.2\%) indicated television as their source of information. One hundred $(24.2 \%)$ indicated radio while
\end{abstract}

Correspondence: Eghosasere Sunday Omozuwa, Department of Obstetrics and Gynaecology, Edo State University Uzairue, Edo State, Nigeria. E-mail: sunnyeghe@yahoo.com

Key words: Pregnant women; awareness; knowledge; perception; COVID-19.

Conflict of interest: The authors have no conflict of interest to declare.

Availability of data and materials: All data generated or analyzed during this study are included in this published article.

Ethics approval and consent to participate: A written permission was obtained from the Head of Department of Obstetrics and Gynaecology, Central Hospital Benin City and all the pregnant women who participated in the study signed a written consent and approval before participating in the study

Informed consent: Written informed consent was obtained from a legally authorized representative(s) for anonymized patient information to be published in this article.

Received for publication: 3 November 2020.

Revision received: 13 May 2021.

Accepted for publication: 14 May 2021.

This work is licensed under a Creative Commons Attribution NonCommercial 4.0 License (CC BY-NC 4.0).

${ }^{\circ}$ Copyright: the Author(s), 2021

Licensee PAGEPress, Italy

Annals of Clinical and Biomedical Research 2021; 2:116

doi:10.4081/acbr.2021.116
$92(22.2 \%)$ implicated friends. One hundred and ninety seven (46.9\%) of the respondents had good knowledge of COVID-19 while $68(16.2 \%)$ had poor knowledge. There was a high level of awareness of COVID-19 among the pregnant women attending Antenatal clinic in central hospital Benin City and majority of them got their information from the television.

\section{Introduction}

\section{Background of study}

Coronavirus disease 2019 (COVID-19) is an infectious viral disease caused by severe acute respiratory syndrome coronavirus2 (SARS CoV-2), which affects mainly the respiratory system and was first discovered during an outbreak in China December 2019. ${ }^{1}$ The disease is transmitted through direct contact with respiratory droplets of an infected person (generated through coughing and sneezing). Individuals can also contact it through touching of infected surfaces such as eyes, nose and mouth. While contact with contaminated objects and surfaces have been also identified as a major route of transmission. ${ }^{1,2}$ COVID-19 was declared as a pandemic by the World Health Organization (WHO) ${ }^{2} 11^{\text {th }}$ of March 2020 and the disease has spread across more than 6 continents including Africa since it was reported in Wuhan China. Globally COVID-19 has led to 3.68 million cases with over 258 thousand deaths while in Nigeria 2,950 confirmed cases with 98 deaths. ${ }^{2,3}$ Every aspect of Human life is affected by COVID-19 pandemic and a worldwide public health response has been engaged to address the impact. Currently, focus has been on the high-risk populations, including older people and people with serious underlying medical conditions, which could obscure the specific risks and needs of other susceptible populations. ${ }^{3}$ Pregnant women are presently recognized as a population at increased risk of the disease. ${ }^{4}$ In pregnancy, women experience altered immunological and physiological response, with adverse complications that might make them more vulnerable to bacterial or viral respiratory infections, such as influenza, Severe Acute Respiratory Syndrome (SARS) and Middle East Respiratory Syndrome (MERS). Beyond the virus-specific risks, illnesses with high fever in the first trimester of pregnancy are associated with specific birth defects, such as neural tube defects, miscarriages leading to high fetal wastage. ${ }^{4,5}$ Quite a number of reports have been conflicting and inconclusive as to whether vertical transmission of SARS-CoV-2 can occur in pregnancy or not. Scanty data on the effect of COVID-19 and adverse pregnancy outcomes are available and studies already published seem to be reassuring that pregnant women with COVID-19 might not be at increased risk for severe complications or adverse reproductive health outcomes. However, these studies have been limited to case series and case reports and lack sufficient numbers to merit the lack of risk or complication attributable to COVID-19 infection in pregnancy. ${ }^{4-6}$ 
This study aimed at determining the level of awareness, knowledge and perception about COVID-19 that can help in the dissemination of appropriate scientific information about the disease among pregnant women attending antenatal clinics. However multiple strategies are needed to be deployed to address the knowledge gaps surrounding the effect of COVID-19 in pregnancy, such as sentinel surveillance and seroprevalence surveys. ${ }^{7-10}$

\section{Materials and Methods}

The study was carried out in a General Hospital Benin City. Benin City which is the capital of Edo State and the state is located in the South-south geo-political zone of Nigeria. It is bounded in the north and east by Kogi State, in the south by Delta State and in the west by Ondo State. The state has a landmass of 19,794 square kilometers and lies between latitudes 05014 " $\mathrm{N}$ and 070 34' $\mathrm{N}$, and between longitudes 050 4' E and 060 45' E. Central Hospital Benin is a secondary health facility owned and managed by the Edo State Government. The health facility is a 500 bedded health facility providing services such as out-patient, general medical, surgical, dental and paediatric services. There are 10 clinical departments in the health facility namely anaesthesiology, paediatrics, dentistry, family medicine, medicine, obstetrics and gynaecology, ophthalmology, surgery, psychiatry and radiology. Central Hospital was used due to the fact that large population of pregnant women obtained treatment from government-owned health facilities.

\section{Study population}

All selected pregnant women attending Antenatal clinics and who gave their consent during the period of the study were utilized while pregnant women who refused to give consent to participate in the study were left out. The study was carried out over a two months period. Planning and proposal writing were carried out, data collection in one month and analysis and final write-up in was carried out over the last one month (May to July, 2020).

The sample size was determined using the formula based on a degree of error of $5 \%$ and $95 \%$ confidence interval.

$$
\mathrm{n}=\mathrm{n}=\frac{\mathrm{z}^{2} \mathrm{Pq}}{\mathrm{d}^{2}}
$$

where:

$\mathrm{n}=$ the minimum sample size required for the study

$\mathrm{P}=60 \%$ which is the proportion of knowledge of COVID19among pregnant in a study carried out in Abakalili, Nigeria, 2020

$\mathrm{q}=1.0-\mathrm{P}$

$\mathrm{d}=$ degree of precision at the 0.05

$\mathrm{Z}=$ the standard normal deviate (1.96), which correspond to $95 \%$ confidence interval.

Therefore:

$$
\begin{aligned}
& \mathrm{n}=\frac{(1.96)^{2}(0.61)(0.39)}{0.05^{2}}=365.56 \\
& \mathrm{n}_{\mathrm{rl}}=\text { non response rate }=(10 \% \text { or } 0.1) \\
& \text { Therefore, } \mathrm{nf}=\frac{356.56}{1.0-0.1}=\frac{356.56}{0.9}=406.1 \\
& \mathrm{n}_{1}=406
\end{aligned}
$$

However, a total of 420 pregnant women was involved in this study.

This study was a cross-sectional descriptive study.

Systematic sampling technique was utilized for this study. The first study participant was selected using a simple random sampling technique by balloting.

A self-administered questionnaire on awareness, knowledge and perception of COVID-19 infection was administered to the participant for data collection. The questionnaire was developed following review of literatures on the WHO recommendations on the measures to prevent human-to-human transmission of COVID19 infection. The study questionnaire was divided into four areas: i) socio-demographic characteristics (i.e., age, parity, marital status, area of residence, occupation, participant's level of education, and husband's level of education); ii) media exposure to access information about coronavirus infection pandemic; iii) knowledge about preventive measures against Coronavirus (COVID-19) infection (i.e., ever heard about coronavirus infection pandemic, multiple variables regarding symptoms, what to do when the participants suspect to have developed the symptoms and iv) perception on covid19. The questionnaire were self-administered by the authors and some residents in department and filled by the eligible pregnant women to the best of their knowledge.

\section{Occupation classification}

Occupation will be classified based on the International Standard Classification of Occupations.

Skill level 1: includes office cleaners, freight handlers, garden laborers, farmers and kitchen assistants etc.

Skill level 2: includes butchers, bus drivers, accounts clerks, tailors, shop sales assistants, police officers, hair dressers, building electricians, and mechanics etc.

Skill level 3: includes shop managers, medical laboratory technicians, technicians etc.

Skill level 4: includes sales and marketing managers, engineers, teachers, medical practitioners, Musicians, theatre nurses and computer systems analysts etc. ${ }^{11}$

\section{Scoring of knowledge}

Knowledge of COVID-19 was scored for correctness. A total of thirteen (13) questions were used to assess knowledge. A score of ' 1 ' mark was given for each correct answer and ' 0 ' mark for incorrect answer. Minimum and maximum scores were calculated as 0 and 13 respectively and scores were converted to percentages and graded as follows, scores $49.9 \%$ and below were categorized as poor knowledge, scores $50.0 \%$ to $69.9 \%$ were categorized as fair knowledge and scores $70.0 \%$ and above were categorized as good knowledge.

\section{Ethical considerations}

This was sought and obtained from the ethics and research committee of Central Hospital Benin City and permission to conduct the study was obtained from the head of department Obstetrics and Gynecology and informed consent from participants.

\section{Data Analysis}

The data obtained was analyzed using SPSS version 20.0 statistical package. Mean and standard deviation (SD) were used to describe continuous variables and proportions for categorical data. chi-square $\left(\chi^{2}\right)$ was used for group comparisons to determine the significance of observed differences or association where applicable. 


\section{Results}

A total of 420 pregnant women participated in the study. The finding of their results were as follows.

\section{Section A: Sociodemographic characteristics of preg- nant women}

One hundred and thirty-four $(31.9 \%)$ of the respondents were aged $30-34$ years and $131(31.2 \%)$ were $25-29$ years. Three hundred and eighty eight $(92.4 \%)$ of the respondents were married while $26(6.2 \%)$ were single. Two hundred and twenty $(52.4 \%)$ of the respondents had secondary level of education and $165(39.5 \%)$ had tertiary education. Two hundred and eighteen $(51.9 \%)$ of the respondents had skill level II jobs and 79 (18.8\%) had skill level IV jobs.

Two hundred and twenty-nine $(54.5 \%)$ of the respondents were had parity of $2-4$ while $101(24.0 \%)$ had a parity of 1 . One hundred and sixty seven $(39.8 \%)$ were between 28 - 32 weeks gestation and $84(20.0 \%)$ were 33 - 36 weeks into their pregnancy while $81(19.3 \%)$ were term pregnancies $(37-40$, Table 1$)$.

Four hundred and fourteen $(98.6 \%)$ of the respondents were aware of COVID-19 and 274 (66.2\%) indicated television as their source of information. One hundred $(24.2 \%)$ indicated radio while $92(22.2 \%)$, indicated friends (Table 2).

One hundred and sixty one $(38.3 \%)$ of the respondents defined COVID-19 as a viral infection, $84(20.0 \%)$ said they did not know how to define it while $43(10.2 \%)$ mentioned an infectious disease (Table 3, Figure 1).

Fever was the commonest COVID-19 symptom familiar to the respondents as $378(90.0 \%)$ indicated it, followed by cough reported by $369(87.9 \%)$ and difficulty breathing by $364(86.7 \%)$.

Three hundred and forty-eight $(82.9 \%)$ of the respondents knew the main symptoms of COVID-19, 325 (77\%) had knowledge of the risk factors, $215(51 \%)$ knew about the mode of transmission while $375(89.3 \%)$ reported that contacts of COVID19 cases should be isolated for 14 days.

One hundred and ninety seven (46.9\%) of the respondents had good knowledge of COVID-19while $68(16.2 \%)$ had poor knowledge (Figure 2, Table 4).

Eighteen $(60.0 \%)$ of the respondents aged 40 years or more

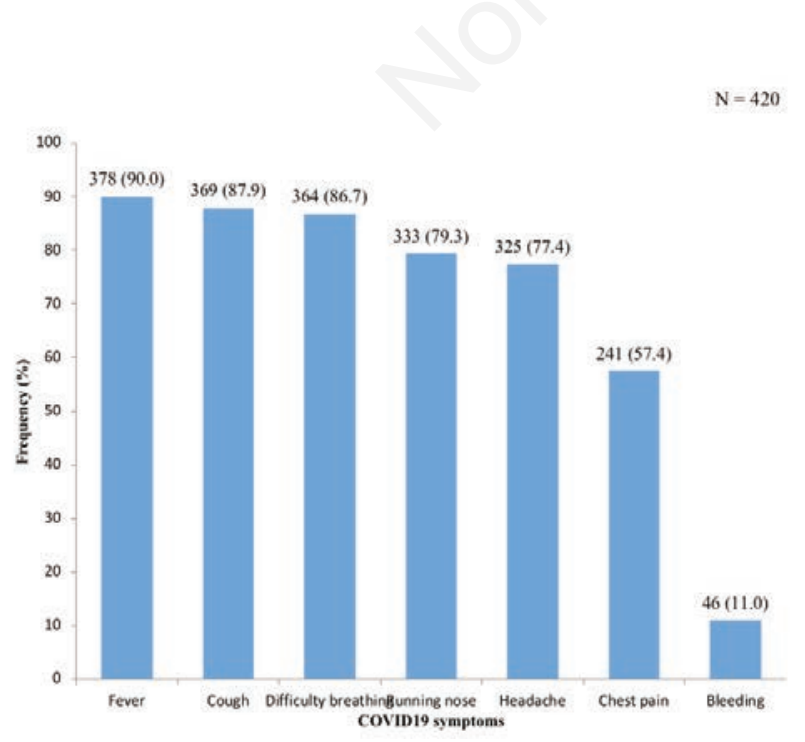

Figure 1. Respondents' knowledge of the symptoms of COVID-19.
Table 1. Sociodemographic characteristics of the respondents.

\begin{tabular}{|c|c|c|}
\hline Variable & Frequency & $\%$ \\
\hline $\begin{array}{l}\text { Age (years) } \\
15-19 \\
20-24 \\
25-29 \\
30-34 \\
35-39 \\
\geq 40\end{array}$ & $\begin{array}{c}5 \\
59 \\
131 \\
134 \\
61 \\
30\end{array}$ & $\begin{array}{c}1.2 \\
14.0 \\
31.2 \\
31.9 \\
14.5 \\
7.1\end{array}$ \\
\hline $\begin{array}{l}\text { Marital status } \\
\text { Single } \\
\text { Married } \\
\text { Divorced } \\
\text { Separated } \\
\text { Cohabiting } \\
\end{array}$ & $\begin{array}{c}26 \\
388 \\
1 \\
3 \\
2\end{array}$ & $\begin{array}{c}6.2 \\
92.4 \\
0.2 \\
0.7 \\
0.5\end{array}$ \\
\hline $\begin{array}{l}\text { Level of education } \\
\text { No formal education } \\
\text { Primary } \\
\text { Secondary } \\
\text { Tertiary }\end{array}$ & $\begin{array}{c}9 \\
26 \\
220 \\
165\end{array}$ & $\begin{array}{c}2.1 \\
6.2 \\
52.4 \\
39.3\end{array}$ \\
\hline $\begin{array}{l}\text { Occupational class (ILO) } \\
\text { Unemployed } \\
\text { Skill level I } \\
\text { Skill level II } \\
\text { Skill level III } \\
\text { Skill level IV }\end{array}$ & $\begin{array}{c}36 \\
67 \\
218 \\
20 \\
79\end{array}$ & $\begin{array}{c}8.6 \\
16.0 \\
51.9 \\
4.8 \\
18.8\end{array}$ \\
\hline $\begin{array}{l}\text { Parity } \\
\quad 0 \\
1 \\
2-4 \\
\geq 5\end{array}$ & $\begin{array}{c}73 \\
101 \\
229 \\
17\end{array}$ & $\begin{array}{c}17.4 \\
24.0 \\
54.5 \\
4.0\end{array}$ \\
\hline $\begin{array}{l}\text { Estimated gestational ag } \\
\quad \leq 12 \\
13-27 \\
28-32 \\
33-36 \\
37-40 \\
>40\end{array}$ & $\begin{array}{c}3 \\
82 \\
167 \\
84 \\
81 \\
3\end{array}$ & $\begin{array}{c}0.7 \\
19.5 \\
39.8 \\
20.0 \\
19.3 \\
0.7\end{array}$ \\
\hline
\end{tabular}

had good knowledge of COVID-19 compared to 19 (32.2\%) of those aged $20-24$ years. This association was statistically significant $(\mathrm{p}=0.011)$.

Table 2. Respondents awareness and definition of COVID-19.

\begin{tabular}{lcc} 
Variable & Frequency & $\%$ \\
Awareness & & \\
$\quad$ Yes & $414(98.6)$ & 98.6 \\
$\quad$ No & 6 & 1.4 \\
Source of information* & $\mathrm{n}=414$ & \\
$\quad$ Television & 274 & 66.2 \\
Radio & 100 & 24.2 \\
Friends & 92 & 22.2 \\
Hospital & 71 & 17.1 \\
Church & 35 & 8.5 \\
\hline Market & 30 & 7.2 \\
Respondents' definition of COVID-19 & & \\
Viral infection & 161 & 38.3 \\
Do not know & 84 & 20.0 \\
An infectious disease & 43 & 10.2 \\
Corona virus infection & 42 & 10.0 \\
A deadly disease & 26 & 6.2 \\
Respiratory infection & 18 & 4.3 \\
Others** & 46 & 11.0 \\
\hline
\end{tabular}

*Multiple responses offered. ${ }^{* *}$ Other responses included air borne disease, infection of the immune system, an incurable sickness, an epidemic, cough, fever and kills people 
Eighty seven (52.7\%) of the respondents with tertiary level of education had good knowledge of COVID-19 while none of those without formal education had good knowledge. This was a significant association $(\mathrm{p}<0.001)$.

Fifteen $(75.0 \%)$ and $47(59.5 \%)$ of the respondents with skill levels III and IV respectively had good knowledge compared to 26 $(38.8 \%)$ of those with skill level I occupation.

Nine $(52.9 \%)$ of the respondents with parity of 5 or more had good knowledge of COVID-19compared to 25 (34.2\%) of those with parity of 0 . This association was statistically significant $(\mathrm{p}=0.021)$.

\section{Section B: Perception of COVID-19}

Three hundred and thirty nine $(80.7 \%)$ of the respondents were of the impression that COVID-19 will finally be successfully controlled. Three hundred and twenty one $(76.4 \%)$ agreed that Nigeria will win the battle against COVID-19 (Table 5).

\section{Discussion}

COVID-19 being a relatively new virus has gained extensive interest in the research world, however there has been sparse literature from Africa. This study delved into this topic to elucidate the level of knowledge and perception of the pregnant women regarding it. About two thirds of the women were aged $25-34$ years, this represents the optimal age for pregnancy in marriage with minimal risk of congenital abnormality. ${ }^{12}$ However almost a quarter were 35 years or more, showing that there is an increasing trend of getting pregnant at older years. This could be linked to advances in the fight for the education of the girl child further culminating in them wanting to complete their education before considering marriage leading to late marriages. ${ }^{13}$ It is emphasized by the findings in this study that most of the women had a minimum of secondary school education and 2 in 5 women had tertiary level of education. This however has the adverse effect of increasing incidence of subfertility, miscarriages, depression and also congenital diseases. ${ }^{13}$ There is need to ensure a balance between the academic and social lives of the girl child so as to allow for the previous societal norms of relatively earlier marriages and also furtherance of education. Some societies allow for the women to complete their higher education in their matrimonial homes, usually sponsored by the husbands. Though this may be an increased burden on young husbands, it tackles the problem of both education and marrying early enough to ensure healthy home and healthy children. The finding that more than half of the women had skill level II occupations (comprising of hair dressers, tailors, caterers etc.) contrasts with the earlier finding of good education. It however depicts the true nature of the work environment in Nigeria and most developing countries where nonprofessional vocations favor employment of men more than women. ${ }^{14}$ Thus these women are pushed to 'learn work' even though they had university degrees. The few that can't get work, try trading of commodities such as clothes, make up, accessories etc. while the rest further their education to Masters level or remain as housewives. The finding that most of the women were married is a reflection of the positive effects of the cultural norms on the study population.

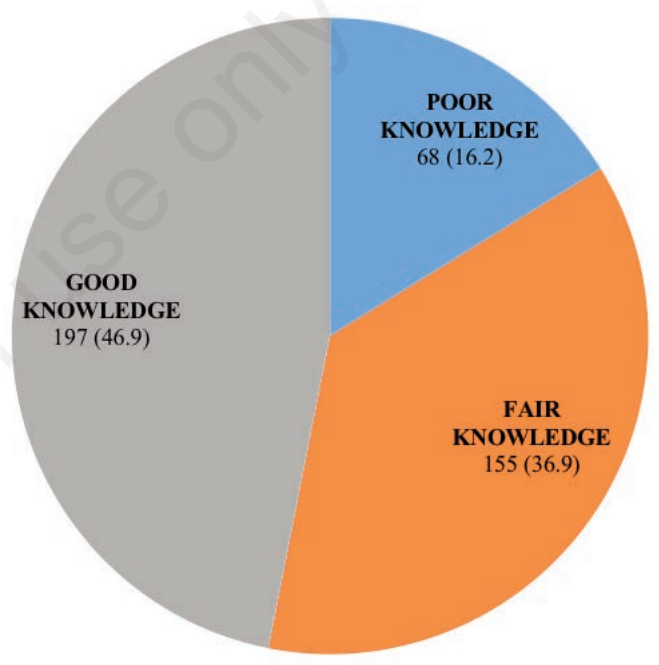

Figure 2. Respondents' knowledge of COVID-19.

Table 3. Respondents' knowledge of COVID-19(N = 420).

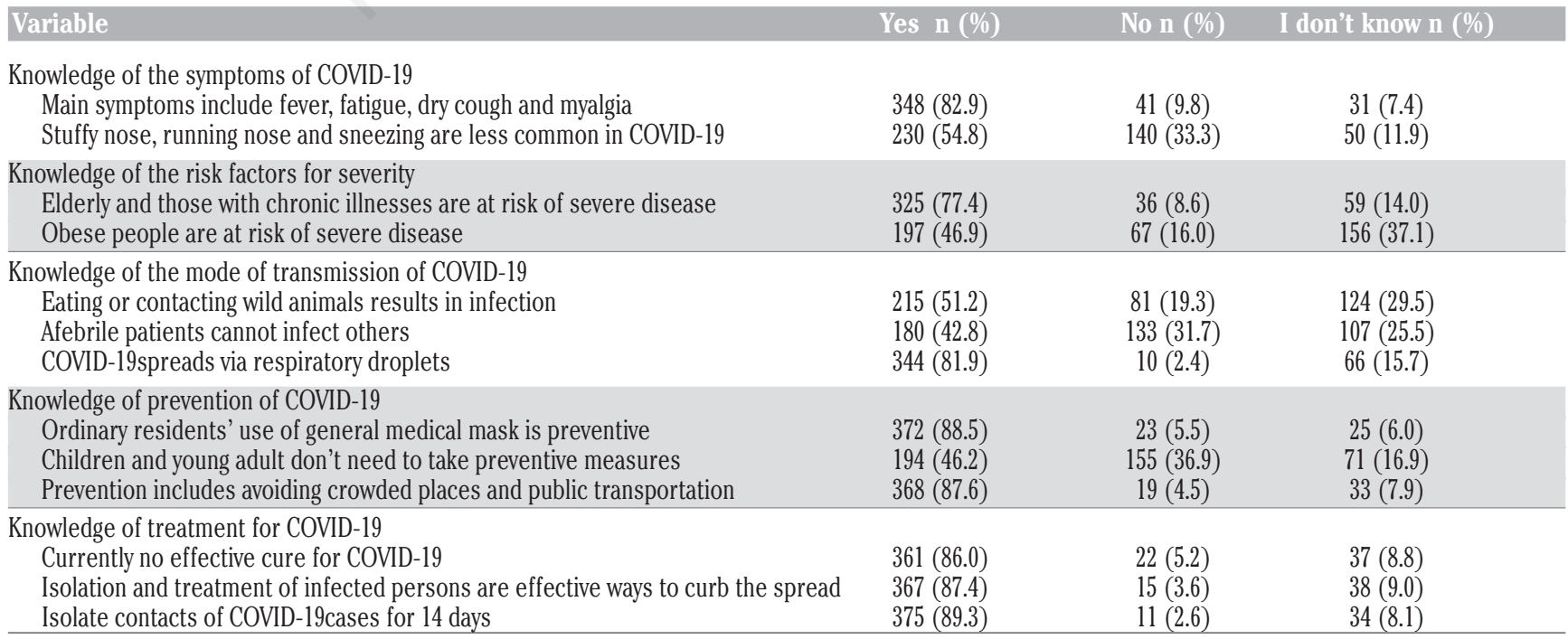


More than half of the women were multiparous before the index pregnancy, while a quarter were in their second pregnancy and $4 \%$ were grand multiparous. Previous Nigerian studies showed incidence of grand multiparity in Ibadan and Calabar as $6.1 \%$ and $8.7 \%$ respectively. ${ }^{15}$ The Grand multiparity has been linked to increasing adverse outcome in pregnancy and has been implicated in diabetes mellitus, antepartum hemorrhage, malpresentation, higher cesarean section rate, postpartum hemorrhage, iron deficiency anemia, and a high perinatal mortality rate. ${ }^{16}$ However, our study findings align with prevalence of grand multiparity in developed countries which may reflect the efforts put in over the last few decades to promote family planning and contraceptive use.

More than half of the pregnancies were viable preterm while about 2 in 5 were term pregnancies. The knowledge of COVID-19 and steps to take to prevent its spread are particularly important at these stages so as to protect both mother and child after delivery.
Most of the women were aware of COVID-19, which is not surprising owing to the total shut down of most activities in the country with extensive media coverage of the disease infecting prominent personalities. This tallies with a previous study done in the North central Nigeria. ${ }^{17}$ Also not surprising television being the commonest source of information. Other media sources were implicated including radio while a few mentioned friends. This use of traditional media was corroborated by a previous study done in the country. ${ }^{18}$ The results exposed that all the respondents had incomplete knowledge about the corona virus, most defined it as a viral infection and others termed it just as an infectious disease. Generalized awareness though good, may be harmful without sufficient knowledge of the disease. Although there have been numerous health education seminars on television and radio, little attention has been given to internet and social media means which are the most used form of media by the essentially young population

Table 4. Sociodemographic, obstetric characteristics and respondents' knowledge of COVID-19.

\begin{tabular}{|c|c|c|c|c|c|}
\hline Variable & \multicolumn{3}{|c|}{ Knowledge of COVID-19 } & Test statistic & p value \\
\hline 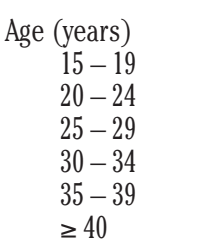 & $\begin{array}{c}0(0.00) \\
16(27.10) \\
14(10.70) \\
25(18.70) \\
6(9.80) \\
7(23.30)\end{array}$ & $\begin{array}{c}1(20.00) \\
24(40.70) \\
57(43.50) \\
42(31.30) \\
26(42.60) \\
5(16.70)\end{array}$ & $\begin{array}{l}4(80.00) \\
19(32.20) \\
60(45.80) \\
67(50.00) \\
29(47.50) \\
18(60.00)\end{array}$ & $X^{2}=23.04$ & $0.01^{*}$ \\
\hline $\begin{array}{l}\text { Marital status } \\
\text { Single } \\
\text { Married } \\
\text { Divorced } \\
\text { Separated } \\
\text { Cohabiting }\end{array}$ & $\begin{array}{c}3(11.50) \\
64(16.50) \\
0(0.00) \\
0(0.00) \\
1(50.00)\end{array}$ & $\begin{array}{c}10(38.50) \\
143(36.90) \\
1(100.00) \\
1(33.30) \\
0(0.00)\end{array}$ & $\begin{array}{c}13(50.00) \\
181(46.60) \\
0(0.00) \\
2(66.70) \\
1(50.00)\end{array}$ & $\mathrm{FE}=5.04$ & 0.82 \\
\hline $\begin{array}{l}\text { Level of education } \\
\text { No formal } \\
\text { Primary } \\
\text { Secondary } \\
\text { Tertiary }\end{array}$ & $\begin{array}{c}6(66.70) \\
4(15.40) \\
49(22.30) \\
9(5.50)\end{array}$ & $\begin{array}{c}3(33.30) \\
11(42.30) \\
72(32.70) \\
69(41.80)\end{array}$ & $\begin{array}{c}0(0.00) \\
11(42.30) \\
99(45.00) \\
87(52.70)\end{array}$ & $\mathrm{FE}=37.95$ & $<0.00 *$ \\
\hline $\begin{array}{c}\text { Occupational clas } \\
\text { Unemployed } \\
\text { Skill level I } \\
\text { Skill level II } \\
\text { Skill level III } \\
\text { Skill level IV }\end{array}$ & $\begin{array}{c}9(25.00) \\
14(20.90) \\
40(18.30) \\
0(0.00) \\
5(6.30)\end{array}$ & $\begin{array}{c}9(25.00) \\
27(40.30) \\
87(39.90) \\
5(25.00) \\
27(34.20)\end{array}$ & $\begin{array}{l}18(50.00) \\
26(38.80) \\
91(41.70) \\
15(75.00) \\
47(59.50)\end{array}$ & $X^{2}=22.58$ & $0.00 *$ \\
\hline $\begin{array}{l}\text { Parity } \\
\quad 0 \\
1 \\
2-4 \\
\quad \geq 5\end{array}$ & $\begin{array}{l}11(15.10) \\
18(17.80) \\
34(14.80) \\
5(29.40)\end{array}$ & $\begin{array}{c}37(50.70) \\
27(26.70) \\
88(38.40) \\
3(17.60)\end{array}$ & $\begin{array}{c}25(34.20) \\
56(55.40) \\
107(46.70) \\
9(52.90)\end{array}$ & $X^{2}=14.95$ & $0.02 *$ \\
\hline $\begin{array}{l}\text { Estimated gestati } \\
\qquad \begin{array}{l}\leq 12 \\
13-27 \\
28 \mathrm{v}-32 \\
33-36 \\
37-40 \\
>40\end{array}\end{array}$ & $\begin{array}{l}\text { (weeks) } \\
1(33.30) \\
15(18.30) \\
32(19.20) \\
14(16.70) \\
6(7.40) \\
0(0.0)\end{array}$ & $\begin{array}{c}0(0.00) \\
26(31.70) \\
57(34.10) \\
40(47.60) \\
32(39.50) \\
0(0.0)\end{array}$ & $\begin{array}{c}2(66.70) \\
41(50.00) \\
78(46.70) \\
30(35.70) \\
43(53.10) \\
3(100.0)\end{array}$ & $\mathrm{FE}=17.08$ & 0.07 \\
\hline
\end{tabular}

*Significant.

Table 5. Respondents' perception of the fight against COVID-19( $\mathrm{N}=420)$.

\begin{tabular}{lccc}
\hline Variable & Agree n (\%) & Indifferent n (\%) & Disagree n (\%) \\
COVID-19will finally be successfully controlled & $339(80.7)$ & $45(10.7)$ & $36(8.6)$ \\
Nigeria will win the battle against COVID-19 & $321(76.4)$ & $56(13.3)$ & $43(10.2)$ \\
\hline
\end{tabular}


of Nigeria. The public has been kept updated with daily COVID19 incidence data online, little attention has been given to spread basic information about the virus, mode of transmission, pathophysiology, clinical features and treatment. Most of the respondents knew that fever, cough and difficulty breathing were symptoms of COVID-19 while about half could distinguish between common cold and COVID-19.

Most of the women were misinformed as they felt COVID-19 disease can be gotten from eating or contacting with wild animals. This may be due to the information obtained at the early stages that the disease was gotten from eating bats in China and the women felt they could contract the same disease from eating wild animals in Nigeria. Such information is unfounded and may tell negatively on the bush meat and seafood market in the country. Surprisingly most of the women felt that afebrile patients cannot infect others which is another point to be corrected as majority of the people with COVID-19 are asymptomatic and actively spreading the disease. This misinformation may stop the people from using safety precautions in the general public and thus controlling the disease would be harder.

Most of the women knew that COVID-19 spreads by respiratory droplets and thus the use of general medical mask, avoiding crowded places and public transport are preventive. Most of the women in this study also correctly stated that there is currently no effective cure but isolation of cases and their contacts is effective enough to curb the spread of the disease. Another misinformation portrayed by the women in this study was the finding that two thirds felt that children and young adults do not need to take precautions. This may have been built on the principle that these groups aren't prone to sever disease but it creates a loophole in the herd immunity efforts aimed at by the government and the healthcare workforce. Children and young adult may not have severe disease but can serve as asymptomatic carriers in the spread of this disease infecting their older contacts. However the population had satisfactory knowledge of the prevention of COVID-19 comparable to a similar study done in Abakaliki, Nigeria. ${ }^{19}$

Almost half of the women had good knowledge of COVID-19 while one in six women had poor knowledge. This is lower than the proportion $(60.9 \%)$ in a study done in Abakaliki, Nigeria. ${ }^{19,20}$ Knowledge is key in checking the spread of the disease. The practice of safety precautions against the disease is dependent on the knowledge of the disease. Zhong et al. ${ }^{21}$ reported the existence of a positive correlation between practice of safety precautions against COVID-19 and level of knowledge among the individuals they studied in China.

Women age of 40 years or more were more likely to have good knowledge as it was shown in a similar study. ${ }^{20}$ Populations older than 40 years are known to still indulge in the practice of seeking most of their information from television and radio which were the commonest sources of information in this study. Though this finding is encouraging, more still has to be done to reach out to the younger population of women through question and answer seminars online or short videos shared via social media channels.

The link between higher parity and good knowledge of COVID-19 in this study may not be unconnected to the women's age as grand multiparous women were more likely to have good knowledge compared to those with lower parity. This is in line with a previous study ${ }^{20}$ that uses a focus group discussion comprising of those with parity of 0,1 or 2 for health education interventions during antenatal clinics visits.

It is not surprising that women with tertiary education were more knowledgeable concerning COVID-19 but disheartening is the finding that none of those with no formal education had good knowledge of the disease. Also those with lower skill level occupations such as traders and farmers showed poor knowledge of COVID-19.

There have been extensive health education outreaches to different marketplaces and neighborhoods but apparently these have not been effective enough. The healthcare workers at the antenatal clinics may now serve as a good source of information on COVID19. There is need to focus on this population in order to win the fight against the deadly disease.

Most of the women were optimistic that COVID-19 will finally be successfully controlled and three quarters could vouch that Nigeria will win the battle against COVID-19. This contradicts a previous study where the respondents perceived that the government is not doing enough to curtail COVID-19 in Nigeria. ${ }^{17}$ The Nigerian population has put a lot of faith in the hard working healthcare workforce and in the government but such a feat can only be achieved by every individual working together to win this war. Everybody has his role to play by practicing safety precautions including using facemasks, physical distancing, avoiding touching nose and mouth, avoiding crowded places and reporting to healthcare facility when symptomatic. Many countries have shown good control of this disease and this was achieved by efficient collaboration between the health workers, government and the population.

In the course of the study, there were lot of knowledge gaps and misinformation about COVID-19being a novel virus especially in the developing countries where many socio-cultural variables operate. Many questionnaires were poorly filled and were invalidated and prompted going to the field several occasions.

\section{Conclusion and Recommendations}

There was a high level of awareness of COVID-19 among the pregnant women attending antenatal clinics in central hospital Benin City but with some knowledge gaps translated into fair knowledge among the women. There was generally an optimistic perception of the fight against COVID-19 among the women. Factors predisposing to good knowledge of COVID-19 included age of 40 or more, higher parity $(\geq 5)$, higher level of education (secondary or more) and higher skill level occupations (III or IV).

There is need to scale up health education efforts using the internet and social media platforms so as to reach the younger age groups. This could be in the form of question and answer formats and online seminars. Pregnant women should maintained physical distancing in the antenatal clinics and they should be allowed to ask questions to clear all their misinformation.

\section{References}

1. Rasmussen SA, Smulian JC, Lednicky JA, et al. Coronavirus disease 2019 (COVID-19) and pregnancy: what obstetricians need to know. Am J Obstet Gynecol 2020;222:415-26.

2. Kerr SM, Parker SE, Mitchell AA, et al. Periconceptional maternal fever, folic acid intake, and the risk for neural tube defects. Ann Epidemiol 2017;27:777-82.

3. Dong L, Tian J, He S, et al. Possible vertical transmission of SARS-CoV-2 from an infected mother to her newborn. JAMA 2020;323:1846-8.

4. Zhu H, Wang L, Fang C, et al. Clinical analysis of 10 neonates born to mothers with 2019-nCoV pneumonia. Transl Pediatr 2020;9:51-60. 
5. Frey MT, Meaney-Delman D, Bowen V, et al. Surveillance for emerging threats to pregnant women and infants. J Womens Health (Larchmt) 2019;28:1031-6.

6. Wilder-Smith A,Wei Y, Araújo TVB, et al. Understanding the relation between Zika virus infection during pregnancy and adverse fetal, infant and child outcomes: a protocol for a systematic review and individual participant data meta-analysis of longitudinal studies of pregnant women and their infants and children. BMJ Open 2019;9:e026092.

7. Mizumoto K, Kagaya K, Zarebski A, Chowell G. Estimating the asymptomatic proportion of coronavirus disease 2019 (COVID-19) cases on board the Diamond Princess cruise ship, Yokohama, Japan, 2020. Euro Surveill 2020;25:2000180.

8. Eaton JW, Rehle TM, Jooste S, et al. Recent HIV prevalence trends among pregnant women and all women in sub-Saharan Africa: implications for HIV estimates. AIDS 2014;28:S50714.

9. Brooks SK, Webster RK, Smith LE, et al. The psychological impact of quarantine and how to reduce it: rapid review of the evidence. Lancet 2020;395:912-20.

10. Sahu KK, Lal A, Mishra AK. COVID-2019 and pregnancy; a plea for transparent reporting of all cases. Acta Obstet Gynecol Scand 2020; published online March 19, https://doi.org/10.1111/aogs. 13850

11. International Labour Office. International Standard Classification of Occupations: ISCO-08. Geneva: ILO;2012:12-16.

12. Ooki S. Maternal age and birth defects after the use of assisted reproductive technology in Japan, 2004-2010. Int J Womens Health 2013;5:65-77.

13. Orazulike NC, Jeremiah I, Green KI, Uzoigwe SA. Effect of age on childbearing in Port Harcourt, Nigeria. Int J Biomed Sci 2015;11:82-5.

14. Enfield S. Gender roles and inequalities in the Nigerian labour market. K4D Helpdesk Report. Brighton, UK: Institute of Development Studies; 2019.

15. Emechebe CI, Njoku CO, Eyong EM, et al. The social class and reasons for grand multiparity in Calabar, Nigeria. Trop J Obstet Gynaecol 2016;33:327-31.

16. Alsammani MA, Ahmed SR. Grand multiparity: risk factors and outcome in a tertiary hospital: a comparative study. Mater Sociomed 2015;27:244-247.

17. Reuben RC, Danladi MMA, Saleh DA, Ejembi PE. Knowledge, attitudes and practices towards COVID-19: An epidemiological survey in North-Central Nigeria. J Community Health 2020: https://doi.org/10.1007/s10900-02000881-1

18. Olapegba PO, Ayandele O, Kolawole SO, et al. COVID-19 knowledge and perceptions in nigeria. PsyArXiv Preprints 2020 https://doi.org/10.31234/osf.io/j356x

19. Anikwe CC, Ogah CO, Anikwe IH, et al. Coronavirus disease 2019; Knowledge, attitude, and practice of pregnant women in a tertiary hospital in Abakaliki, southeast Nigeria. Int J Gynecol Obstet 2020: doi:10.1002/ijgo.13293

20. Nwafor JI, Aniukwu JK, Anozie BO, et al. Pregnant women's knowledge and practice of preventive measures against COVID-19 in a low-resource African setting. Int J Gynaecol Obstet 2020;150:121-3.

21. Zhong BL, Luo W, Li HM, et al. Knowledge, attitudes, and practices towards COVID-19 among Chinese residents during the rapid rise period of the COVID-19 outbreak: A quick online cross-sectional survey. Int J Biol Sci 2020;16:1745-52. 